\title{
Dialytic Approach in Hemodialysis (HD) Patients with Hydrocephalus
}

\author{
David Tovbin* and Osama Darawshe \\ Department of Nephrology, Israel \\ *Corresponding author: David Tovbin, Department of Nephrology, Israel
}

$\overline{\text { ARTICLE INFO }} \quad$ ABSTRACT

Received: 蔧 March 01, 2019

Published: March 11, 2019
Keywords: Hydrocephalus; Hemodialysis; Urea; Blood Flow Rate; Dementia; Gait Disturbance

Citation: David Tovbin, Osama Darawshe. Dialytic Approach in Hemodialysis (HD) Patients with Hydrocephalus. Biomed J Sci \& Tech Res 15(4)-2019. BJSTR. MS.ID.002740.

\section{Opinion}

Cognitive dysfunction and neurological disturbances are common in Hemodialysis (HD) patients [1] and may be induced by chronic processes, acute events and a combination of both. Patients starting HD who develop acute neurologic disturbances, though measures to prevent the disequilibrium syndrome [2] were implemented, deserve special attention. Possible acute causes include ischemic and hemorrhagic strokes due to intra-dialytic hypotension, high blood pressure and/or anticoagulation on the background of the increased frequency and severity of diabetes mellitus, hypertension, atherosclerosis, arteriolosclerosis and atrial fibrillation in incident HD patients [3]. Falls, trauma, vascular disease, anticoagulation and polycystic kidney disease predispose to subdural and subarachnoid hematomas [4]. An additional acute cause for neurological symptoms, which is infrequent though reported to be more common in dialysis patients, is hydrocephalus [5]. Acute events at start of hemodialysis due to hydrocephalus may occur in patients with previous diagnosis of hydrocephalus or in previously undiagnosed patients.

Hydrocephalus consists of widening of the ventricles due to excessive accumulation of the Cerebrospinal Fluid (CSF). Obstructive hydrocephalus is due to disturbed CSF circulation and communicating hydrocephalus is due to impaired CSF absorption or uncommonly excessive production. Hydrocephalus can be with high or normal CSF pressure. Normal pressure hydrocephalus is a chronic adult-onset communicating hydrocephalus, usually caused by impaired CSF absorption that develops gradually usually in elderly patients [6]. Chronic hydrocephalus in adults can manifest as a triad of gait disturbance, the most common initial symptom, urinary incontinence and dementia, with or without symptoms and signs of increased intracranial pressure, such as headache, papilledema and localizing signs [6]. In addition to acute events at start of HD, increased risk of hydrocephalus, obstructive and even more common communicating, has been reported in Taiwanese dialysis patient cohort [5]. Explanations were that hydrocephalus may develop after subarachnoid hemorrhage and meningitis, which are more frequent in ESRD patients and may cause inflammation and arachnoid granulation fibrosis interfering with CSF absorption [7]. In addition, periventricular ischemic lesions associated with increased frequency of hypertension and vascular disease may cause weakening and dilation of the ventricles and increased local venous resistance, resulting in reduced CSF absorption [8]. Treatment of hydrocephalus consists of surgical ventriculo-peritoneal or lumboperitoneal shunts [9]. In HD patients, we suggest combining the surgical therapy with specific dialytic approach. Urea removal in HD induces a gap between blood and brain cells urea levels leading to increased brain cell water, which is typical in the disequilibrium syndrome during HD initiation [2].

Patients with hydrocephalus may be more susceptible to this adverse effect as previously reported [10]. In another patient 
shorter and more frequent dialysis sessions along with intravenous mannitol resulted in satisfactory clinical response [11]. We reported a similar effect of correlation between the increase in intraocular pressure during HD and rate of urea removal manifested by post dialysis urea rebound and suggested to reduce blood flow and thus urea removal rates in HD patients with glaucoma [12]. We assume that even urea removal with only mild gap and increase in brain cell water during chronic HD, can exacerbate clinical picture in susceptible HD patients including those with hydrocephalus. Possible putative mechanism may be that even small increases in brain cell water may further interfere with CSF absorption and augment widening of the ventricles with excess CSF. Thus, in addition to the surgical procedures, reducing blood flow and urea removal rates and thus possibly the urea gap and the increase in cell brain water may be helpful to prevent and ameliorate symptoms in such patients.

Recently, we observed dialytic exacerbation of headache, vomiting and/or neurologic symptoms in 3 incident HD patients with known or newly suspected normal pressure hydrocephalus. Those patients were dialyzed after appearance of symptoms of headache and /or vomiting with blood flow of 200-225 instead of $300 \mathrm{ml} /$ minute prolonging time of dialysis to assure adequacy of dialysis delivery. 1 patient was diagnosed with normal pressure hydrocephalus and underwent lumbar-peritoneal shunt placement 2 years prior to HD. 1 of the newly diagnosed patients underwent ventricular-peritoneal shunt placement, which was considered but not performed in the third patient. Reduced blood flow rate of 200$225 \mathrm{ml} /$ minute was helpful in reliving symptoms. In my opinion, this approach may be favorable to using short frequent dialysis as previously reported [11], since the increase in brain cell water may be prevented, and not just stopped after a shorter time of HD.

In Conclusion, normal pressure hydrocephalus needs to be considered in HD patients with exacerbated headache, vomiting or the typical neurologic picture during HD. In addition to surgical procedures, reduced blood flow and urea removal rates may be helpful to prevent and ameliorate symptoms in these patients.

\section{References}

1. Kurella Tamura M, Yaffe K (2011) Dementia and cognitive impairment in ESRD: diagnostic and therapeutic strategies. Kidney Int 79: 14-22.

2. Patel N, Dalal P, Panesar M (2008) Dialysis disequilibrium syndrome: a narrative review. Semin Dial 21: 493-498.

3. Iseki K, Fukiyama K (1996) Predictors of stroke in patients receiving chronic hemodialysis. Kidney Int 50(5): 1672-1675.

4. Sood P, Sinson GP, Cohen EP (2007) Subdural Hematomas in Chronic Dialysis Patients: Significant and Increasing. Clin J Am Soc Nephrol 2(5): 956-959.

5. Wang IK, Lin CL, Cheng YK, Chou CY, Liang CC, et al. (2016) Increased risk of hydrocephalus in long-term dialysis patients. Nephrol Dial Transplant 31(5): 807-813.

6. Marmarou A, Young HF, Aygok GA, Sawauchi S, Tsuji O, et al. (2005) Diagnosis and management of idiopathic normal-pressure hydrocephalus: a prospective study in 151 patients. J Neurosurg 102(6): 987-997.

7. Hebb AO, Cusimano (2001) Idiopathic normal, pressure hydrocephalus: a systematic review of diagnosis and outcome. Neurosurgery 49(5): 1166-1184

8. Bradley WG, Whittemore AR, Watanabe AS, Davis SJ, Teresi LM, et al. (1991) Association of deep white matter infarction with chronic communicating hydrocephalus: implications regarding the possible origin of normal-pressure hydrocephalus. AJNR Am J Neuroradiol 12: 31-39.

9. Boon AJ, Tans JT, Delwel EJ, Egeler Peerdeman SM, Hanlo PW, et al (2000) The Dutch normal-pressure hydrocephalus study. How to select patients for shunting? An analysis of four diagnostic criteria. Surg Neurol 53: 201-207.

10. Flannery T, Shoakazemi A, McLaughlin B, Woodman A, Cooke S (2008) Dialysis disequilibrium syndrome: a consideration in patients with hydrocephalus. Case report. J Neurosurg Pediatr 2(2): 143-145.

11. O’Sullivan P, Sajjad J, Abrar S and Marks C. (2015). Case Report. Headache during haemodialysis in a patient with shunt: a cause for concern? BM] Case Rep.

12. Tovbin D, Belfare N, Shapira S, Friger M, Rosenthal G, et al. (2002) High postdialysis urea rebound (PDUR) can predict intradialytic (ID) increase in intraocular pressure (IOP) in dialysis patients with lowered ID hemoconcentration. Nephron 90: 181-187.

\section{ISSN: 2574-1241}

DOI: $10.26717 / B J S T R .2019 .15 .002740$

David Tovbin. Biomed J Sci \& Tech Res

(c) (i) This work is licensed under Creative Commons Attribution 4.0 License

Submission Link: https://biomedres.us/submit-manuscript.php

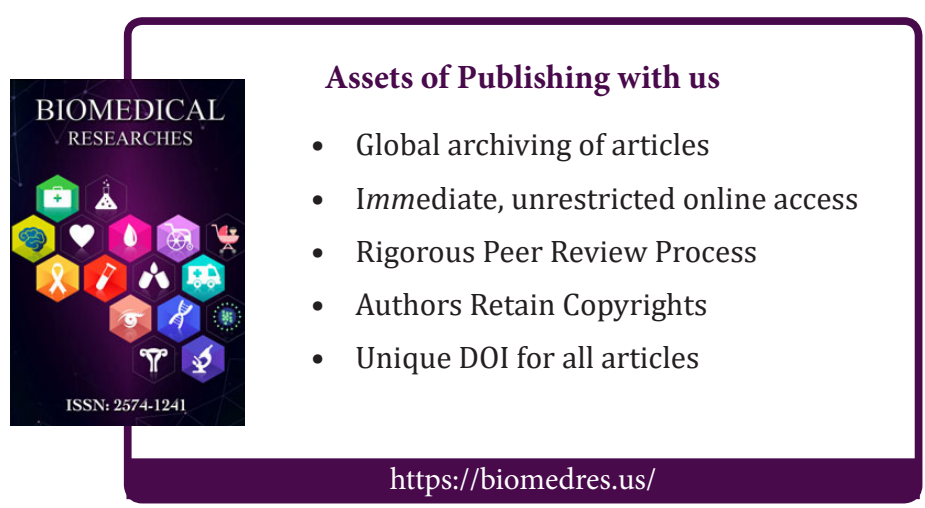

